OPEN ACCESS

Edited by:

Fan Tong,

Lawrence Berkeley National

Laboratory, United States

Reviewed by:

Bo Zhang,

China University of Mining and Technology, Beijing, China

Hongbo Duan,

University of Chinese Academy

of Sciences, China

*Correspondence:

Yingchao Chen

chenyingchao614@163.com

Songlin Tang

yttangsonglin@163.com

Specialty section:

This article was submitted to

Sustainable Energy Systems and Policies,

a section of the journal

Frontiers in Energy Research

Received: 25 November 2020

Accepted: 13 April 2021

Published: 09 June 2021

Citation:

Hu $Y$, Chen $Y$, Tang S, Feng $L$ and

Huang C (2021) An Explanation of Energy Return on Investment From

an Entropy Perspective.

Front. Energy Res. 9:633528. doi: 10.3389/fenrg.2021.633528

\section{An Explanation of Energy Return on Investment From an Entropy Perspective}

\author{
Yan Hu${ }^{1}$, Yingchao Chen ${ }^{2,3 *}$, Songlin Tang ${ }^{2,3 *}$, Lianyong Feng ${ }^{4}$ and Chen Huang ${ }^{5,6}$ \\ ' SINOPEC Petroleum Exploration and Production Research Institute, Beijing, China, ${ }^{2}$ School of Economics, Shandong \\ Technology and Business University, Yantai, China, ${ }^{3}$ Shandong Synergistic Innovation Center of Energy and Economy, \\ Yantai, China, ${ }^{4}$ School of Economics and Management, China University of Petroleum, Beijing, China, ${ }^{5}$ School of Public \\ Policy and Management, University of Chinese Academy of Sciences, Beijing, China, ${ }^{6}$ Institutes of Science \\ and Development, Chinese Academy of Sciences, Beijing, China
}

Low-carbon energy transformation is a major trend in world energy development, and measures to mitigate carbon emissions can vary substantially in terms of the energy they require. A common method of evaluating energy use in energy resource exploitation is energy return on investment (EROI). One of the criticisms of EROI concerns uncertainty regarding the input and output factors for the calculation. To make the issue clear, we interpret $\mathrm{EROI}$ in terms of entropy, which is the most basic concept in physics. We consider an energy resource exploitation system to be a kind of dissipative structure and construct a basic entropy analysis framework for an energy resource exploitation system. We then derive the relationship between $\mathrm{EROI}$ and entropy change. The theory of $\mathrm{EROI}$ is consistent with the basic requirement for a dissipative structure, which is that the total entropy change must be negative. EROI is a method of using entropy theory to evaluate energy resource exploitation. It is inappropriate and unnecessary to quantify all factors as energy units as the input and output factors are multidimensional while energy is a one-dimensional standard. Future development of the EROI method should be guided by entropy theory. A series of EROI related indicators will increase its application and policy significance.

Keywords: EROI, net energy, entropy, dissipative structure, energy resource exploitation

\section{INTRODUCTION}

Energy return on investment (EROI) is a method of calculating the energy returned to the economy and society compared to the energy required to obtain that energy and, thus, to measure the net energy produced for society (Odum, 1973; Mulder and Hagens, 2008; Hall, 2011; Hall et al., 2014). The concept of net energy was first proposed by Odum in 1973, and EROI has been the subject of research for over 40 years (Hall et al., 2014; Xu et al., 2016).

One of the criticisms of EROI concerns uncertainty regarding the input and output factors for the calculation. This is because it is difficult to determine accurate and reasonable input and output factors for energy exploitation activities (Mulder and Hagens, 2008; Hall et al., 2009; Murphy et al., 2011). Input factors include direct energy, non-energy resources (e.g., land, water, time, labor), and embodied energy (e.g., energy consumed by infrastructure construction and material production), while output factors include direct energy output, coproducts, and externalities 
(e.g., carbon emissions, soil erosion, ground and water pollution, loss of habitat, job creation, maintenance of rural communities). In most studies, the calculation is based on standard EROI, which only includes direct and indirect energy and material inputs and outputs. However, standard EROI is highly inaccurate for some energy sources, such as shale gas, biomass energy, and solar energy (Chen et al., 2020). If the input and output factors are not determined strictly, EROI will be one-sided and misleading. Research on EROI calculation and input and output factors is important, otherwise EROI will not be useful for policy.

Research on EROI focuses on the economic process of energy resource exploitation. As early as 1971, Georgescu-Roegen observed that "the economic process is a process of entropy, wealth is a kind of exploitation system, which is produced in the circulation process of the low-entropy resource consumption as the beginning and the discharge of equal high entropy waste to the environment as the end" (Georgescu-Rogen, 1971). Tsuchida (1991) regards entropy as the value of energy, because entropy is a good representation of value change for humans and because the natural law that the consumption of resources indicates that the consumption process is the process of value creation and entropy production. The focus of EROI on the economic process of energy resource exploitation follows the basic laws of nature. As one of the most fundamental theories of physics, entropy theory has the potential to deepen our understanding of EROI and resolve the criticisms levied against it as method.

In the EROI calculation, what is the basis of the decision which input and output factors should be included in the accounting system? We discuss this issue from the perspective of entropy. We use the concept of entropy under the assumption of a thermodynamically open economy to analyze energy resource exploitation activity and explore the EROI method from an entropy perspective. Ultimately, this paper is to promote further application of EROI theory and method. The article's organizational framework is structed as follows. Section 2 presents the basic theory of EROI and entropy and explains EROI theory from an entropy perspective. Section 3 constructs an analytical diagram for energy resources exploitation and explains EROI method from an entropy perspective. Section 4 discusses the process and result of explanation. Finally, Section 5 summarizes the paper.

\section{THE THEORY OF EROI FROM AN ENTROPY PERSPECTIVE}

\section{Net Energy Theory and EROI}

From an industrial perspective, the general pattern of any energy resource exploitation is that workers use a variety of equipment, materials, and resources and consume a certain amount of energy when extracting the energy resource from nature. Then, the resource is ultimately transformed into secondary and final energy products to meet human demands. The net energy is the amount of energy left over from the gross energy extracted (and processed and delivered) from a primary energy source after the energy needed to sustain extraction, processing and delivery processes has been subtracted (Carbajales-Dale et al., 2014). The recommended method of calculating net energy is EROI (Gilliland, 1975). As Figure 1 shows, EROI focuses on the input and output of energy and the process of energy circulation. To ensure that energy resource exploitation can provide net energy for the development of society, the energy output must be greater than the energy input (Chen et al., 2017a).

The true value of energy to society is the net energy, which is the energy output minus the energy input (Odum, 1973), and social and economic development is based on this net energy surplus (Gilliland, 1975). Each increment in EROI allows more and more work to be done. The energy needs of human beings can be represented as a pyramid (Figure 2). More complex social activities require more energy and, hence, higher EROI from the energy system (Lambert et al., 2014).

\section{Development of the Concept of Entropy}

The theory of entropy originates from thermodynamics, where it represents a state function for measuring the degree of disorder in a system. Entropy was first proposed by Clausius in 1865 and was defined as the "quotient of heat-temperature." The term was used to describe energy in transformation and the direction of that transformation within a system (He and He, 2006). Later, in 1877, Boltzmann proposed a formula, known as the Boltzmann entropy formula, that linked entropy to the microscopic state of a system and the degree of chaos of molecular motion ( $\mathrm{He}$ and He, 2006). In 1948, Shannon connected entropy to information as a quantitative measure of the uncertainty of information source signals (Shannon, 2014). In 1967, Prigogine first proposed a theory of dissipative structures and explained this as an open system at a nonlinear region far from equilibrium that will undergo mutation (Prigogine and Lefever, 1973).

In 1971, Georgescu-Rogen studied the relationship between thermodynamics and the economic process and claimed that the economic process was a process of entropy. The link between entropy and economics was explored in more depth in 1976 by Atsushi Tsuchida, who proposed that what an economic system consumes is not energy or material itself, but the diffusion capacity that is useful for mankind (Xue, 1994). Both production and consumption within an economy can be seen as a kind of consumption of resource diffusion capacity that can be measured using entropy (Tsuchida, 1991; Yu, 1992). In 1980, Rifkin and Howard published Entropy: A New World View. Although it was controversial, the book established a world view based on the law of entropy generation, which has had a profound impact on the system of value judgments in normative economics (Qian, 1990; Zhang, 2006). Since then, debates on entropy and how it should be applied in economics have persisted.

Developments in the theory of entropy and its implementation in engineering have greatly improved society. Clausius first proposed the concept of entropy when he was analyzing the efficiency of heat engines and exploring energy conversion optimization. The scientific beauty of thermodynamic concepts such as energy, exergy, and entropy have been essential in human scientific endeavors, from the development of combustion technology to advancing our understanding of the final frontiers of our universe [perhaps best illustrated by the late Stephen Hawking's (1976) work on black holes]. 


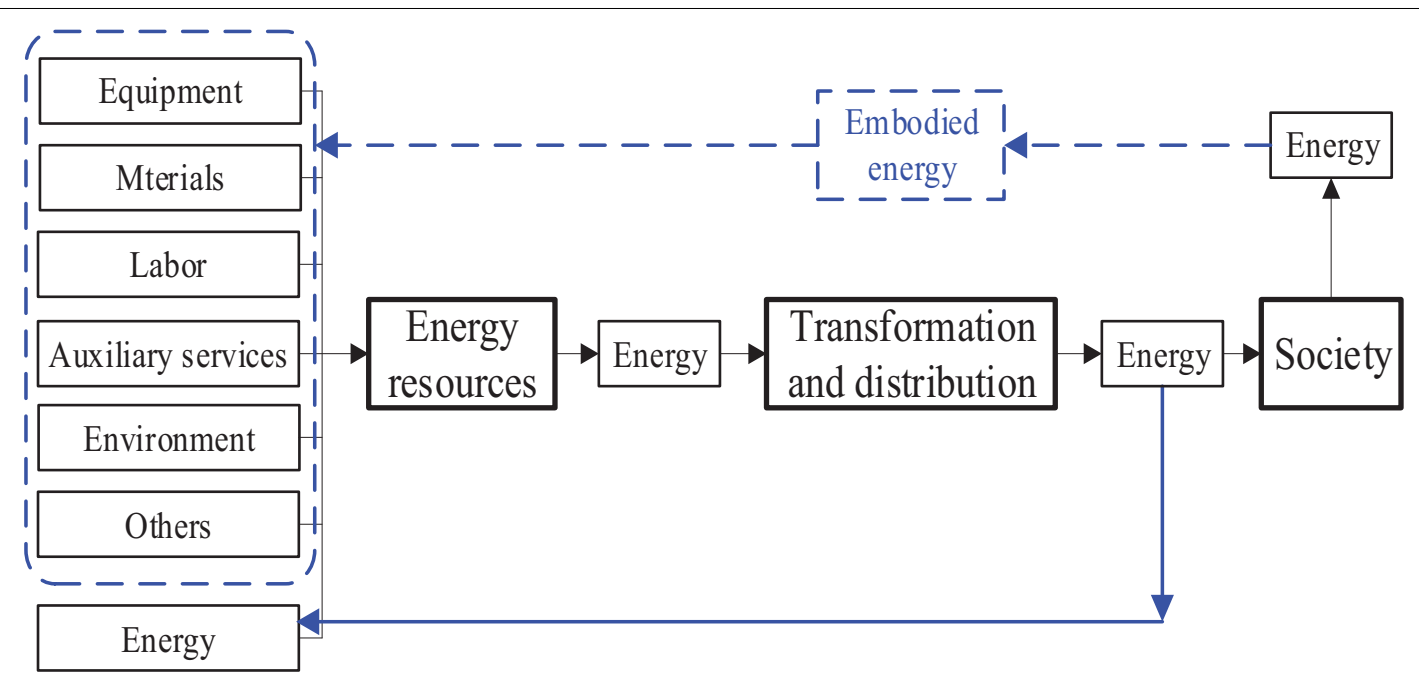

FIGURE 1 | Energy resource exploitation from a material perspective.

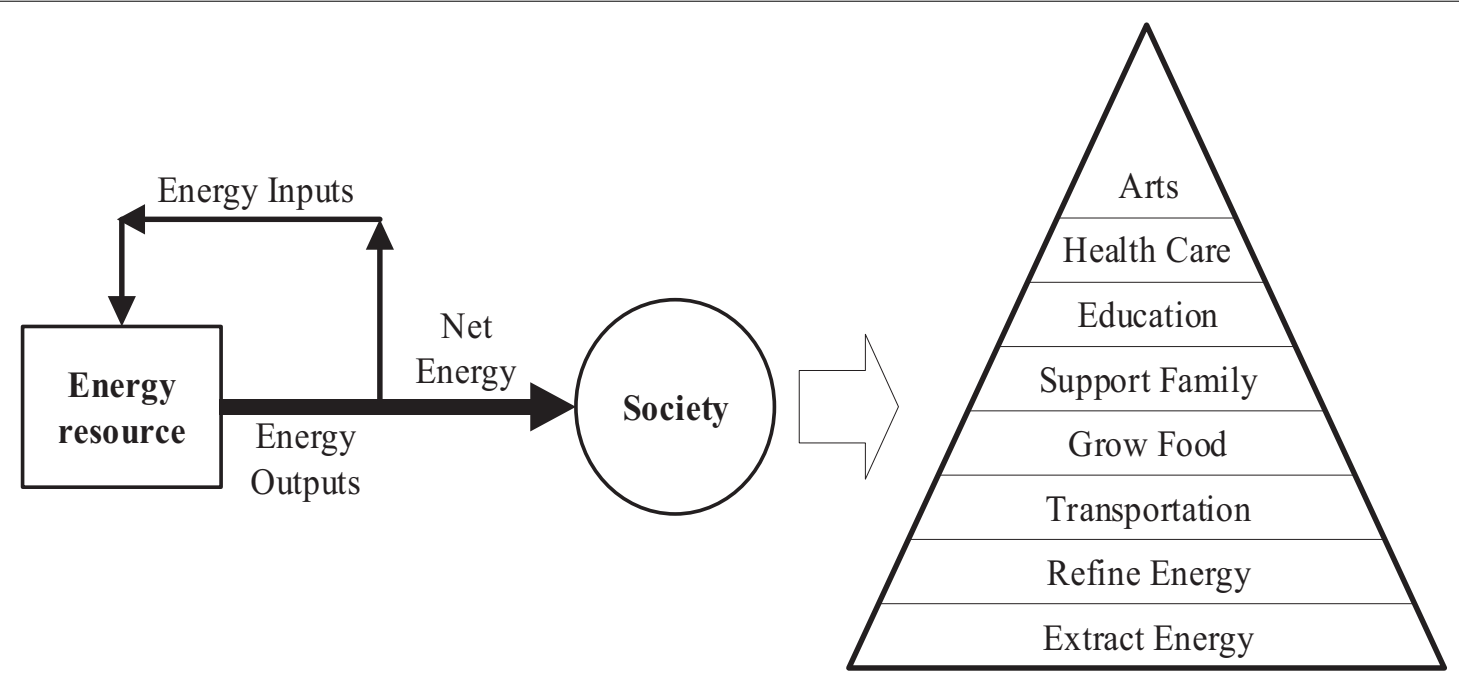

FIGURE 2 | Net energy and pyramid of energetic needs.

Thermodynamic ideas have been used extensively to devise alternative accounts of economics by drawing analogies with physical or natural processes, such as energy usage. It is easy to argue that the transition intermediary of entropy from a thermodynamic system to a social economic system is the correspondence of energy and economic value orientation (Yu, 1992).

The operation of an economic system is a process of transforming nature into value for society, and it may be argued that such transformations mirror energy transformations in the sphere of thermodynamic engineering. However, one must be aware that such analogs are indirect and can be contested (Hammond, 2004). The economic value assigned to a product by the market is different from energetic value in physics. Nevertheless, such metaphors are still useful for illustrative purposes (Van Gool, 1987; Hammond, 2007). From this perspective, the dissipative structure theory and other thermodynamic analogs can be used to explain the significance of entropy to the social economic system, both micro- and macroscopically. This theoretical background renders these methods suitable for further exploration of EROI.

\section{Connecting EROI Theory and Entropy}

The exploitation of energy resources can be regarded as a social-economic-natural complex ecosystem consisting of human activities, physical environments, resource flows, and social culture (Ma and Wang, 1984; Wang and Ouyang, 2012). This ecosystem constantly exchanges energy, material, and information with the outside world. It consumes energy, materials, and labor and produces energy products while discharging waste materials and energy into the environment. Therefore, this energy exploitation system can be regarded as an 
open thermodynamic system involving entropy change, which we can analyze using dissipative structure theory (Wu, 1991; Shi and $\mathrm{Hu}, 2004$; Sun and Li, 2004; Xu et al., 2004).

As Figure 3 shows, any societal economic system is a subsystem of a broader ecosystem, and of which (primary) energy resources are natural components. Thus, an energy resource exploitation system represents the intersection of the subsystem and the wider ecosystem. According to dissipative structure theory, a dissipative structure system is an open system in a state that is far from equilibrium. It exchanges energy and materials with the outside world, thus producing a state of order in time and space or function out of chaos when the external conditions reach a certain threshold (Prigogine, 1967; Shi and Hu, 2004).

It can be assumed that the energy resource exploitation system is a dissipative structure by virtue of the fact that it has the four characteristics of a dissipative structure $(\mathrm{Wu}$, 1995; Shi and Hu, 2004; Xu et al., 2004; Chu, 2005). (1) An energy resource exploitation is an open system, as its normal functioning depends on a continuous exchange of energy, material, and information with an external environment. (2) It is a system that is far from equilibrium, as various factors, including technical progress, the discoveries of new areas for exploitation, production declines, or changes in exploitation policies, continuously disrupt the equilibrium of the system. (3) The energy resource system consists of nonlinear interaction mechanisms, as each subsystem or element of the system promotes as well as restricts other elements, generating positive feedback that upsets the equilibrium state and negative feedback that restricts growth. (4) The system is also subject to fluctuations; the advantages, disadvantages, and disequilibrium of the system generate increasing instability and disorder until mutation occurs over a critical point if one or more factors (such as production, price, or policy) change.

Entropy change $(d S)$ of an open system in time $(\mathrm{dt})$ is the sum of two parts: the internal entropy change $\left(d_{i} S\right)$ produced by the processes inside the system and the external entropy flow $\left(d_{e} S\right)$ resulting from the exchange of energy and materials with the outside world, as shown in Figure 3. It is important to note that a low-entropy resource (e.g., petroleum, construction materials, process water) consumed within the energy resource exploitation system comes from the social economic system and results in entropy production $d_{i} S$ (i.e., $\left.d_{i} S>0\right)$. The energy produced within the energy resource exploitation system is also a low-entropy resource (e.g., crude oil, natural gas, coal, electricity), which originates from the natural environment and is mainly consumed within the social economic system rather than the energy resource exploitation system. Furthermore, the low-entropy resource corresponding to the system's energy production flows into the energy resource exploitation system, which means that the potential for entropy production flows into the energy resource exploitation system, so $d_{e} S$ is negative (i.e., $d_{e} S<0$ ). Conversely, the low-entropy resource corresponding to the energy investment from the social economic system is consumed within the energy resource exploitation system, so $d_{i} S$ is positive. According to dissipative structure theory, the basic requirement of a dissipative structure is a total entropy change that is non-positive $(d S \leq 0)$. This means that the entropy production in the system is not greater than the negative entropy production flowing into the system $\left(d_{i} S \leq\left|d_{e} S\right|\right)$.

From the perspective of entropy, the focus of the energy resource exploitation system is on the quantity and the direction of the flow of entropy, because the system has a particular purpose, namely to provide energy for the development of society. This corresponds to the issue of input and output or cost and benefit in economics. Both dissipative structure theory and EROI focus on the input and output of energy by considering issues of quantity and quality, and both require that the output is not less than the input.

Energy can be explained by entropy. However, entropy is more than an explanation of energy. Processes such as carbon emission and water consumption are also important issues for energy

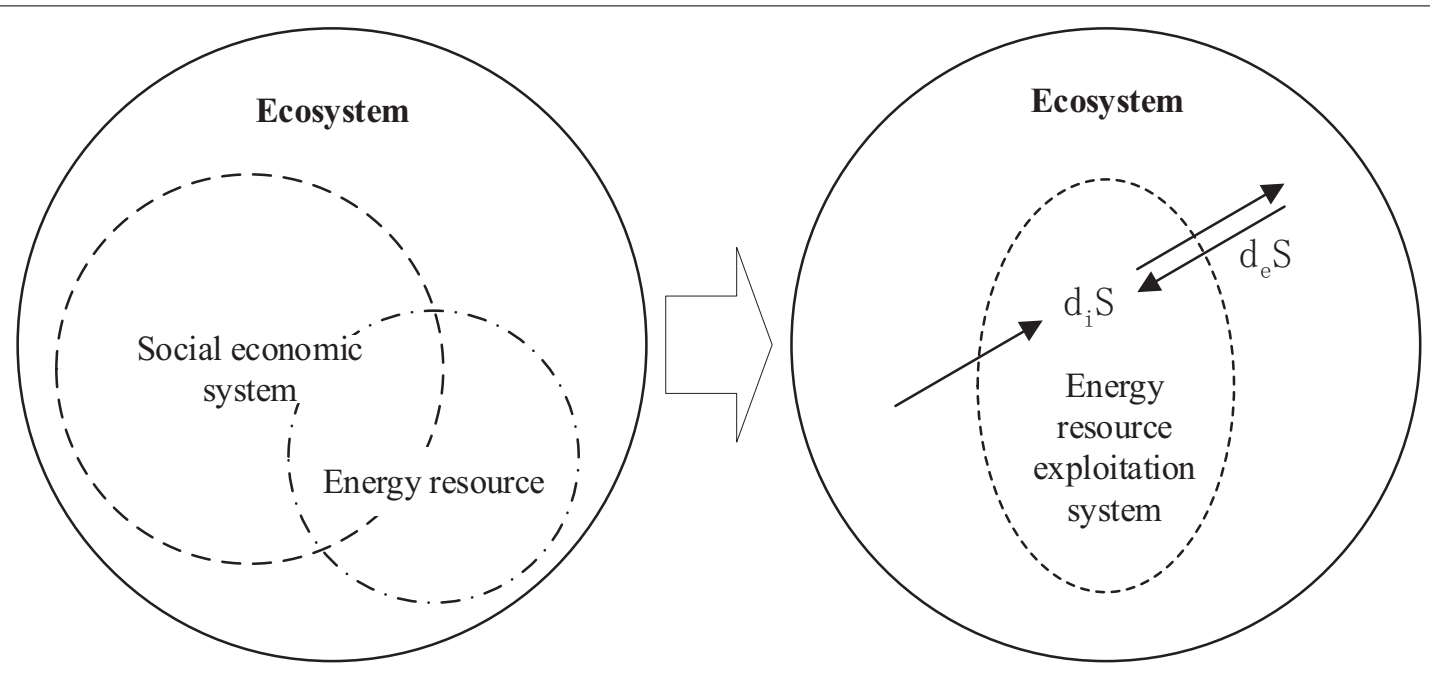

FIGURE 3 | An energy resource exploitation system and its dissipative structure. 
resource exploitation. These issues can be explained by entropy, whereas it can be controversial to explain carbon emission or water consumption in terms of energy. The concept of entropy is broader than energy. In terms of energy production, EROI is consistent with dissipative structure theory, while entropy gives a more profound and general explanation.

\section{THE EROI METHOD FROM AN ENTROPY PERSPECTIVE}

\section{Basic Formula}

The basic formula of dissipative structure theory is as follows:

$$
d S=d_{i} S+d_{e} S
$$

where $d S$ is the total entropy change in time $d t, d_{i} S$ is the internal entropy change, and $d_{e} S$ is the external entropy flow.

The conventional equation for calculating EROI is as follows (Mulder and Hagens, 2008):

$$
E R O I=\frac{\sum_{i=1}^{n} E_{i}^{O}}{\sum_{j=1}^{m} E_{j}^{I}}
$$

where $E_{i}^{O}$ is the energy production (outputs), and $E_{j}^{I}$ is the energy invested (inputs).

In general, different forms of energy are converted into heat equivalents and expressed in calorific values. Taking energy quality into consideration, the equation may be rewritten as follows (Cleveland, 1992; Murphy et al., 2011; Hu et al., 2014):

$$
E R O I=\frac{\sum_{i=1}^{n} \lambda_{i} E_{i}^{O}}{\sum_{j=1}^{m} \lambda_{j} E_{j}^{I}}
$$

where $\lambda$ is the energy quality factor. Depending on one's perspective, energy quality can have different meanings, such as emergy, exergy, and price (Gao et al., 2011).

\section{Connecting the EROI Method and Entropy}

We construct an analytical diagram based on the Carnot heat engine to discuss the relationship between entropy and EROI, as shown in Figure 4. The heat of the non-energy substance and the energy initially invested in the energy resource exploitation system is $Q_{1}$, and the entropy is $S_{1}$. When the substance and the energy invested is consumed, the waste heat and the heat contained in the waste material is $Q_{2}$, and the entropy is $S_{2}$. The useful work produced for exploiting the energy resource is $W_{1}$. The heat contained in the energy products is $Q_{3}$, and the entropy is $S_{3}$. When the energy products are transferred to the social economic system and consumed, the useful work produced for humans is $W_{2}$, the waste heat and heat contained in the waste material is $Q_{4}$, and the entropy is $S_{4}$. The term ER in Figure 4 designates the energy resource. The heat contained in substances (e.g., equipment, raw material) can be interpreted as "embodied energy" that is consumed for producing the non-energy substance. The waste heat and waste

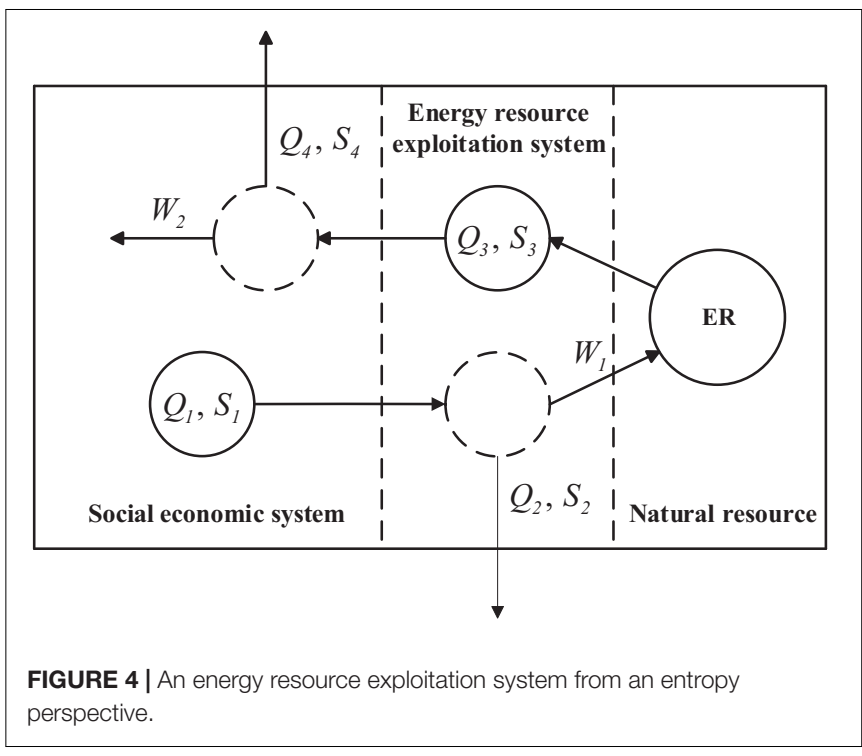

material are discharged into the natural environment. The useful work serves the social economic system and can be used to meet human needs.

The dissipative structure theory formula is in the form of a differential, as shown in formula (1); therefore, it can be assumed that

$$
\begin{aligned}
& d_{i} S=f_{1}{ }^{\prime}(t) d t \\
& d_{e} S=f_{2}{ }^{\prime}(t) d t
\end{aligned}
$$

In time $t$, the accumulative total internal entropy production IS and the accumulative total external entropy flow ES are as follows:

$$
\begin{aligned}
& I S=\int_{a}^{b} f_{1}^{\prime}(t) d t=S_{2}-S_{1} \\
& E S=\int_{c}^{d} f_{2}^{\prime}(t) d t=-\left(S_{4}-S_{3}\right)
\end{aligned}
$$

where $a$ and $b$ are the beginning and end states of the factors invested and consumed in the energy resource exploitation system, respectively, and $c$ and $d$ are, respectively, the beginning and end states of the energy products produced by the energy resource exploitation system and consumed in the economic system of society. The total entropy change $\Delta S$ of the energy resource exploitation system is as follows:

$$
\Delta S=I S+E S
$$

which is calculated as follows:

$$
\Delta S=\left(S_{2}-S_{1}\right)+\left[-\left(S_{4}-S_{3}\right)\right]
$$

If the absolute temperature of the ecosystem is $T(T>0)$, then both sides of Eq. 9 are multiplied by $T$ :

$$
T \Delta S=T\left(S_{2}-S_{1}\right)+T\left(S_{3}-S_{4}\right)
$$


According to Clausius's entropy formula

$$
d S=\frac{\delta Q}{T}
$$

Then Eq. 10 becomes

$$
T \Delta S=\left(Q_{1}-Q_{2}\right)+\left(Q_{4}-Q_{3}\right)
$$

According to the first law of thermodynamics,

$$
\begin{aligned}
& Q_{1}=Q_{2}+W_{1} \\
& Q_{3}=Q_{4}+W_{2}
\end{aligned}
$$

Substituting Eqs. 13, 14) into Eq. 12, then

$$
T \Delta S=W_{1}-W_{2}
$$

Equation 15 shows that entropy can indeed indicate the useful value that is available for humans. In addition, the most basic function of the energy resource exploitation system is to provide the necessary energy for the development of a social economic system. More specifically, the useful value invested in the energy resource exploitation system by humans must be used to gain more useful value (i.e., it is required that $W_{2} \geq W_{1}$ ). This is consistent with the basic requirement of the dissipative structure theory that $\Delta S \leq 0$. If we assume that the ratio of useful value to total energy (direct energy and embodied energy) is $\alpha$, then

$$
\begin{aligned}
& W_{1}=Q_{1} \alpha_{1} \\
& W_{2}=Q_{3} \alpha_{2}
\end{aligned}
$$

Substituting Eqs 16, 17 into Eq. 15, then

$$
T \Delta S=\alpha_{1} Q_{1}-\alpha_{2} Q_{3}
$$

We can simplify Eq. 3 of the EROI calculation as follows:

$$
E R O I=\frac{\lambda_{O} E_{O}}{\lambda_{I} E_{I}}
$$

where $E_{O}$ is the energy output, $E_{I}$ is the energy input, $\lambda_{O}$ is the energy quality factor of the energy output, and $\lambda_{I}$ is the energy quality factor of the energy input. If energy quality is taken to mean useful value, that is, the energy quality factor $\lambda$ is the ratio of useful value to total energy, then

$$
\begin{aligned}
& \lambda_{O}=\alpha_{2} \\
& \lambda_{I}=\alpha_{1}
\end{aligned}
$$

Furthermore, it is obvious that

$$
\begin{aligned}
& E_{I}=Q_{1} \\
& E_{O}=Q_{3}
\end{aligned}
$$

Substituting Eqs. 20-23 into Eq. 19, then

$$
E R O I=\frac{\alpha_{2} Q_{3}}{\alpha_{1} Q_{1}}
$$

If both sides of Eq. 24 are multiplied by $\alpha_{1} Q_{1}\left(\alpha_{1} Q_{1}>0\right)$, then

$$
\alpha_{2} Q_{3}=E R O I \cdot \alpha_{1} Q_{1}
$$

Substituting Eq. 25 into Eq. 18, then

$$
T \Delta S=\alpha_{1} Q_{1}-E R O I \cdot \alpha_{1} Q_{1}
$$

If both sides of Eq. 26 are divided by $\alpha_{1} Q_{1}$, then

$$
\begin{aligned}
& E R O I=-\frac{\Delta S}{\Delta S_{1}}+1 \\
& E R O I=\frac{-\Delta S+\Delta S_{1}}{\Delta S_{1}}
\end{aligned}
$$

where $\Delta S_{1}=\frac{W_{1}}{T}$ indicates the environmental entropy change of the useful work dissipated in the form of heat.

Under the assumption that the energy quality factor is the ratio of useful value to total energy, it can be seen that net energy and $\Delta S$ are almost the same thing. This assumption implies that the use value measured by entropy is presented by energy. Entropy has a more general significance, but it can appear more abstract and less comprehensible. Furthermore, entropy change is more difficult to quantify than EROI, which is more intuitive as an indicator. There are strong connections between entropy and EROI in an open thermodynamic economy. While EROI analysis may appear to be a more concrete approach, entropy is a more holistic approach, albeit at the expense of tractability.

\section{DISCUSSION}

Thermodynamic concepts may be used to theoretically connect EROI and entropy within an economy if the basic assumption that economic properties metaphorically correspond to thermodynamic factors is accepted. Since the days of GeorgescuRogen (1971), biophysical and ecological economists have long argued that entropy, exergy, and other thermodynamic properties are meaningful indicators within economies.

The classical criticism of these ideas revolves around the fact that there are no direct links between thermodynamic properties and various economic values within a complex economy, as discussed by Kovalev (2016). Söllner (1997) and Slesser (1978) independently argued that thermodynamics can via proper use of metaphors and analogs - lead to new insights primarily regarding the absolute limits of economies. Examples of such limits include the finiteness of fossil fuels and other planetary boundaries that are important to consider for the long-term planning of interactions between mankind and nature (Hammond, 2004; Hammond and Winnett, 2006; Haberl et al., 2014; Hall et al., 2014).

Some common input and output factors are summarized in Table 1. It is obvious that there are major differences between the various factors when it comes to ease of measurement and use. This may potentially explain why most EROI studies only cover direct energy inputs, embodied energy inputs, and direct energy outputs (Hall et al., 2014; Chen et al., 2017b). Though the concept of entropy is broader than energy, it cannot 
TABLE 1 | Common input and output factors for EROI analyses.

\begin{tabular}{|c|c|c|c|c|c|}
\hline No. & Input factors & & No. & $\begin{array}{l}\text { Output } \\
\text { factors }\end{array}$ & \\
\hline 1 & Direct energy & & 1 & Direct energy & \\
\hline \multirow[t]{4}{*}{2} & Embodied energy & Material & 2 & Coproducts & \\
\hline & & Equipment & & & \\
\hline & & Infrastructure & & & \\
\hline & & $\cdots \cdots$ & & & \\
\hline \multirow[t]{3}{*}{3} & Resource & Land & 3 & $\begin{array}{l}\text { Social } \\
\text { consequences }\end{array}$ & Jobs \\
\hline & & Water & & & $\begin{array}{l}\text { Maintenance } \\
\text { of rural } \\
\text { communities }\end{array}$ \\
\hline & & $\ldots \cdots$ & & & $\ldots \ldots$ \\
\hline 4 & $\begin{array}{l}\text { Labor and } \\
\text { technology }\end{array}$ & & & & \\
\hline \multirow[t]{3}{*}{5} & $\begin{array}{l}\text { Ecological service } \\
\text { (Environmental) }\end{array}$ & $\begin{array}{l}\text { Carbon } \\
\text { emissions }\end{array}$ & & & \\
\hline & & Habitat & & & \\
\hline & & $\cdots \cdots$ & & & \\
\hline 6 & Auxiliary services & & & & \\
\hline 7 & Time & & & & \\
\hline
\end{tabular}

measure all the factors listed in Table $\mathbf{1}$ using a single unit. The factors are multidimensional, whereas energy is a onedimensional standard. This demonstrates the deficiency of trying to uniformly quantify the various input and output factors as simple energy units.

For EROI to accurately measure net energy, it is necessary to calculate all energy input and output factors as correctly as possible. However, this is quintessentially the same as the argument that to maximize economic benefits, economic evaluation methods for energy resource exploitation use economic benefits as a sole criterion and leave out other non-economic factors such as energy efficiency, environmental impacts, which has been criticized by EROI scholars ( $\mathrm{Hu}, 2013$; Chen et al., 2017b). The various kinds of input and output factors listed in Table 1 cannot be fully represented by net energy alone. This implies that EROI does not account for the importance of other factors, such as land, water, labor, and technology. Energy is the most basic and indispensable resource for the development of human society, but that does not mean as long as there is enough energy, it can produce, renew or restore other input factors correspondingly. For example, less than one square mile of the 296 square miles of land that has been disturbed by tar sands development in Alberta of Canada has been certified as reclaimed. Struzik (2014), it is almost impossible to recreate a wetland that takes thousands of years to form. Although the land petroleum industry has reclaimed may look good in newspaper, magazine, and television advertisements, it is not the original wetland-rich landscape that was dominated by forest and shrubby fens. In theory, the calculation of EROI should include all kinds of factors, as energy resource exploitation entails even more input and output factors than those listed in Table $\mathbf{1 .}$ However, we must recognize the limitations of EROI, and future EROI research should acknowledge this rather than attempting to quantify and compare all kinds of input and output factors as energy units.

\section{CONCLUSION}

Essentially, EROI is a method of using entropy theory to evaluate energy resource exploitation. An energy resource exploitation system acts as a bridge between a social system and natural energy resources. It can be considered a dissipative structure system as it has the characteristics of being an open system that is far from a state of equilibrium state and that entails nonlinear interaction mechanisms and continuous fluctuation. In terms of energy resource exploitation activities, both EROI and entropy theory focus on the input and output of useful value and on a comparative analysis from a physical point of view. In an EROI analysis, net energy is the real contribution of an energy resource exploitation system, whereas net energy is representative of the total entropy change in the entropy analysis. Entropy has a more general significance, as it can also explain processes such as carbon emission and water consumption. However, it may appear more abstract, less comprehensible, and more difficult to quantify than energy. The focus of EROI is the flow of energy in energy resource exploitation. Thus, EROI is essentially a method of applying entropy theory from an energy perspective.

It is inappropriate and unnecessary to quantify all factors as energy units. The input and output factors involved in energy resource exploitation are multidimensional, whereas energy is a one-dimensional standard. Recognizing this limitation can advance research on the EROI methodology. Future development of the EROI method should be guided by entropy theory. Juxtaposing some important factors with energy or focusing on the use value of energy may be promising new research directions. For example, Huang et al. (2019) have come up with EROC and EROW, and Chen et al. (2020) have proposed ExEROI.

Energy return on investment leads to the loss of many meaningful information because of the data is aggregated into a simple ratio (González-López, 2021), but EROI is not useless for policy. EROI is a method to reveal the law of energy flow in energy exploitation activities. After establishing a series of EROI related indicators, the application and policy significance of EROI will increase. Along with net present value (NPV), EROI should be considered when evaluating the feasibility of energy resource exploitation projects. Physical indicators, such as EROC and EROW, should be further developed, especially against a background of low-carbon energy transformation. Further research is required on methods such as EROI, EROC, and EROW, as they can play an important role in optimizing the path of energy substitution. Although we establish a useful framework for energy resource exploitation, it does simplify some details. For instance, it does not distinguish between feedstock and processing energy. However, this study mainly focuses on theory and method analysis. Future research on the topic should include case studies. Another avenue for further study would be to address how the standard EROI method and related auxiliary indexes could be improved. 


\section{DATA AVAILABILITY STATEMENT}

The original contributions presented in the study are included in the article/supplementary material, further inquiries can be directed to the corresponding authors.

\section{AUTHOR CONTRIBUTIONS}

YH: methodology and funding acquisition. YC: conceptualization, methodology, and writing - original draft. ST: methodology and funding acquisition. LF: supervision. $\mathrm{CH}$ : methodology.

\section{REFERENCES}

Carbajales-Dale, M., Barnhart, C. J., Brandt, A. R., and Benson, S. M. (2014). A better currency for investing in a sustainable future. Nat. Clim. Chang. 4, 524-527.

Chen, Y., Feng, L., Tang, S., Wang, J., Huang, C., and Höök, M. (2020). Extendedexergy based energy return on investment method and its application to shale gas extraction in China. J. Clean. Prod. 260:120933. doi: 10.1016/j.jclepro.2020. 120933

Chen, Y., Feng, L., and Wang, J. (2017a). Correlation analysis of energy return on investment and discounted cash flow. Pet. Sci. Bull. 2: 309.e318.

Chen, Y., Feng, L., Wang, J., and Höök, M. (2017b). Emergy-based energy return on investment method for evaluating energy exploitation. Energy 128, 540-549. doi: 10.1016/j.energy.2017.04.058

Chu, H. (2005). Study on Environmental Impact Issues of Industry Produce Based Entropy. Chengdu: Southwest Jiaotong University.

Cleveland, C. J. (1992). Energy quality and energy surplus in the extraction of fossil fuels in the U.S. Ecol. Econ. 6, 139-162. doi: 10.1016/0921-8009(92)90 010-p

Gao, X., Hu, Y., and Feng, L. (2011). Comparison of different energy statistics and general methods. Energy China 33, 21-26.

Georgescu-Rogen, N. (1971). The Entropy Law and the Economic Process. Cambridge: Harvard University Press.

Gilliland, M. W. (1975). Energy analysis and public policy. Science 189, 1051-1056.

González-López, R. (2021). Why energy return on energy investment is not useful for policy. Energy Res. Soc. Sci. 74:101915. doi: 10.1016/J.ERSS.2021.10 1915

Haberl, H., Erb, K. H., and Krausmann, F. (2014). Human appropriation of net primary production: patterns, trends, and planetary boundaries. Annu. Rev. Environ. Resour. 39, 363-391. doi: 10.1146/annurev-environ-121912-09 4620

Hall, C. A. S. (2011). Introduction to special issue on new studies in EROI (Energy Return on Investment). Sustainability 3, 2496-2499. doi: 10.3390/su3122496

Hall, C. A. S., Lambert, J. G., and Balogh, S. B. (2014). EROI of different fuels and the implications for society. Energy Policy 64, 141-152. doi: 10.1016/j.enpol. 2013.05.049

Hall, C. A. S., Balogh, S., and Murphy, D. J. R. (2009). What is the minimum EROI that a sustainable society must have? Energies 2, 25-47. doi: 10.3390/ en20100025

Hammond, G. P. (2004). Engineering sustainability: thermodynamics, energy systems and the environment. Int. J. Energy Res. 28, 613-639. doi: 10.1002/ er.988

Hammond, G. P. (2007). Industrial energy analysis, thermodynamics and sustainability. Appl. Energy 84, 675-700. doi: 10.1016/j.apenergy.2007.01.002

Hammond, G. P., and Winnett, A. B. (2006). Interdisciplinary perspectives on environmental appraisal and valuation techniques. Waste Resour. Manag. 159, 117-130. doi: 10.1680/warm.2006.159.3.117

Hawking, S. W. (1976). Black holes and thermodynamics. Phys. Rev. D. 13, 191-197. doi: 10.1103/PhysRevD.13.191
All authors contributed to the article and approved the submitted version.

\section{FUNDING}

This study was supported by the Doctors Start Funding Projects (No. BS201902) of Shandong Technology and Business University, the National Natural Science Foundation of China (No. 72004122/71874202/71874201/71903114), the National Social Science Fund of China (No. 15BJY052), and by the STandUP for Energy Research Initiative. Science and Technology of Sinopec Group Foundation (No. P18055-2).

He, X., and He, K. (2006). Differentiate and analyse of information entropy and extension alization of entropy. J. Inf. 25, 109-112.

Hu, Y. (2013). The Study of Fossil Fuels EROI and its Implication in China. Beijing: China University of Petroleum.

$\mathrm{Hu}$, Y., Feng, L., Qi, C., and Li, R. (2014). EROI and its application in China-Daqing oil field. China Min. Mag. 9, 30-34.

Huang, C., Gu, B., Chen, Y., Tan, X., and Feng, L. (2019). Energy return on energy, carbon, and water investment in oil and gas resource extraction: methods and applications to the Daqing and Shengli oilfields. Energy Policy 134:110979. doi: 10.1016/j.enpol.2019.110979

Kovalev, A. V. (2016). Misuse of thermodynamic entropy in economics. Energy 100, 129-136. doi: 10.1016/j.energy.2016.01.071

Lambert, J. G., Hall, C. A. S., Balogh, S., Gupta, A., and Arnold, M. (2014). Energy, EROI and quality of life. Energy Policy 64, 153-167. doi: 10.1016/j.enpol.2013. 07.001

Ma, S., and Wang, R. (1984). The social-economic-natural complex ecosystem. Acta Ecol. Sin. 4, 3-11.

Mulder, K., and Hagens, N. J. (2008). Energy return on investment: toward a consistent framework. Ambio 37, 74-79. doi: 10.1579/0044-7447(2008)37[74: eroita]2.0.co;2

Murphy, D. J., Hall, C. A. S., Dale, M., and Cleveland, C. (2011). Order from Chaos: a preliminary protocol for determining the EROI of fuels. Sustainability 3, 1888-1907. doi: 10.3390/su3101888

Odum, H. T. (1973). Energy, ecology, and economics. Ambio 2, 220-227.

Prigogine, I. (1967). Introduction to Thermodynamics of Irreversible Processes, 3rd Edn, New York, NY: Interscience.

Prigogine, I., and Lefever, R. (1973). “Theory of dissipative structures," in Synergetics, ed. H. Haken (Wiesbaden: Springer), 124-135. doi: 10.1007/9783-663-01511-6_10

Qian, S. (1990). A philosophical analysis of the issues of entropy concept. Philos. Res. 6, 58-66.

Shannon, C. E. (2014). A mathematical theory of communication. Bell Lab. Tech. J. 27, 379-423.

Shi, Y., and Hu, Z. (2004). Dissipative structure view of industrial structure evolution. Sci. Sci. Manag. S. T. 25, 59-61.

Slesser, M. (1978). Energy in the Economy. London: Palgrave Macmillan.

Söllner, F. (1997). A reexamination of the role of thermodynamics for environmental economics. Ecol. Econ. 22, 175-201. doi: 10.1016/s09218009(97)00078-5

Struzik, E. (2014). On Ravaged Tar Sands Lands, Big Challenges for Reclamation. Available online at: http://e360.yale.edu/features/on_ravaged_tar_sands_ lands_big_challenges_for_reclamation (accessed January 11, 2019).

Sun, F., and Li, Q. (2004). The theory of dissipative structure and its scientific idea. J. Nat. Sci. Heilongjiang Univ. 21, 76-79.

Tsuchida, A. (1991). Resource Physics. Shanghai: East China Institute of Chemical Technology Press.

Van Gool, W. (1987). The value of energy carriers. Energy 12, 509-518. doi: 10.1016/0360-5442(87)90010-7

Wang, R., and Ouyang, Z. (2012). Social-Economic-natural complex ecosystem and sustainability. Bull. Chin. Acad. Sci. 27, 337-345. 
Wu, J. (1991). Dissipative structure, hierarchy theory and ecosystem. Chin. J. Appl. Ecol. 2, 181-186.

Wu, X. (1995). Negentropy of dissipative structure system and its realizing process. J. Syst. Dialect. 2, 76-79.

Xu, B., Feng, L., Hu, Y., and Wei, W. (2016). Analysis of the development of energy return on investment(EROI) research. China Min. Mag. 25, 42-52.

Xu, D., Wang, Z., and Guo, L. (2004). Entropy analyses and distinguishing of industrial ecological system evolution based on dissipative structure theory. Manag. Sci. China 17, 51-56.

Xue, G. (1994). A new member of interdiscipline: resource physics. J. Tianjin Norm. Univ. Sci. Sci. 23, 40-43.

Yu, W. (1992). The combination of entropy and economics: a new standpoint and method of economics. J. Ind. Technol. Econ. 5, 63-66.
Zhang, Z. (2006). Cognition of the entropy concept and economic problems. Stud. Dialect. Nat. 22, 67-71.

Conflict of Interest: The authors declare that the research was conducted in the absence of any commercial or financial relationships that could be construed as a potential conflict of interest.

Copyright $\odot 2021 \mathrm{Hu}$, Chen, Tang, Feng and Huang. This is an open-access article distributed under the terms of the Creative Commons Attribution License (CC BY).

The use, distribution or reproduction in other forums is permitted, provided the original author(s) and the copyright owner(s) are credited and that the original publication in this journal is cited, in accordance with accepted academic practice. No use, distribution or reproduction is permitted which does not comply with these terms. 